\title{
Risk Minimization in Agribusiness using Soft Computing Technique
}

\author{
Tejaskumar Ghadiyali ${ }^{1}$, Kalpesh Lad $^{2}$ \\ ${ }^{I}$ (UCCC \& SPBCBA \& UACCAIT, Udhna, Surat,Gujarat, India) \\ ${ }^{2}$ (SRIMCA, Uka Tarsadia University, Bardoli, Gujarat, India)
}

\begin{abstract}
India is an agriculture based country and farmer community is the backbone of the agriculture sector. Agribusiness is one of the important segments of agriculture sector. This paper aims to minimize agribusiness risk by deploying the agribusiness knowledge to the farmer community. In this context, this paper intend at predicting agriculture commodity market price using soft computing technique. Such generated knowledge helps farmer community in their decision making and thereby achieving their ultimate goal of profit making.
\end{abstract}

Keywords - Risk Minimization in Agribusiness, Soft computing in Agriculture, Market Price Prediction

\section{Introduction}

Since the origin of mankind, agriculture has been a leading activity of every civilization to exploit natural resources like land for the satisfaction of mankind's basic need-'food'. Agriculture has a noteworthy role to play in the economic development of India. Agriculture sector accounts for 14\% of Gross Domestic Product (GDP) of the Indian economy. About $70 \%$ of the population lives in rural areas and majority of them depend on agriculture as their primary source of income [1]. Thus, Agriculture sector in India provides productive employment to a significantly large section of rural Indian society. This sector also provides raw material for a large number of industries in the trade and industrial development of India. Agricultural extension services such as value addition services, food processing, branding and packaging help in reducing poverty by utilizing modern agriculture system in this domain.

Agribusiness is a key segment for both agricultural growth and industrialization based on agricultural products. Indian agribusiness has many opportunities and scope to grow in the recent times. There are vast opportunities in many sub-domains of agribusiness in India such as Retailing, Branding, Packaging, Export and Value Addition of agriculture products by using technology and business management. Agribusiness development in India helps in the employment of village people, small business development. To develop agribusiness in India, agriculture productivity level should be increased which is currently less than the global average productivity level. Agribusiness including its inter-related manufacturing and trade component contributes 25\% of total GDP of India [1]. In the last five years Indian agribusiness has been growing at 10\% per annum and reaching worth nearly ₹ 17000 billion which is $60 \%$ more than the next largest industryFinancial Services in the economic development of India [2]. By considering the importance of agriculture business sector in the economic development of India, the authors thought about an intelligent environment in the domain of agriculture such as Agriculture Intelligence [3]. In this study author performed risk minimization in this sector using ICT. The authors used soft computing technology-artificial neural network to predict agriculture commodity market price and there by alert the farmer community and help them in their future agribusiness decision making.

The positive factors in agribusiness in India include growing demand of agricultural inputs, organic farming, production of vegetable under green house effect, export of agricultural products, forest resources, vast Coastal line for transportation and micro irrigation system. Therefore after proper utilization of such positive factors in the agriculture sector, Indian agribusiness has a potential to increase this segment from $₹ 17000$ billion to $₹ 36000$ billion by 2020 [2]. There are several challenges in Indian agribusiness which have been discussed in the next topic.

\subsection{Agribusiness Challenges in India}

In agribusiness, the price of the agriculture crop is determined by demand and supply mechanism. Here, the price of the product in the market is not the price that the farmer receives. Expenses like transportation expenses, processing charges, sales brokerage, storage charges etc. are deducted from the market price and the remaining amount, after having the profit of middlemen, wholesaler and retailers, is given to the farmer. In this scenario, in spite of many opportunities from Agriculture to Agribusiness the farmer community has to suffer a lot in terms of the profit margin. Due to the fast modification in the trade scenario of agriculture product, agribusiness process itself has not changed enough to meet the emerging demands of such services. In the new 
millennium, the challenges in Indian agribusiness sector are quite different from those met in the previous decades. Below are some of the agribusiness challenges.

- Agriculture commodity market price information is available but it does not offer sufficient knowledge required by the farmer community.

- To sustain growth in India careful economic evaluation of inputs like seeds, fertilizers, irrigation sources etc before cultivation of agriculture commodity is necessary but it is not available in the existing system.

- The market size is continuously expanding and the farmer market linkage also keeps on increasing, but the agri-business process has not kept pace, which ultimately results in the loss of proper market.

- Due to the intermediate stake holders (e.g. Broker) the direct 'Farmer to Consumer' Agribusiness is very less which results in low profitability to the farmer community.

- Due to lack of proper cleaning, sorting, grading and packaging at the farm level, $10 \%$ of the seed zest are lost before actual trading of the same.

- Due to lack of infrastructure in rural areas, increased demand for the value-added services does not sustain.

To push up and handle smooth agribusiness in India, there is a need of a knowledge based system in the agriculture domain. This study is the first step toward such direction. Thus this study tries to minimize the agribusiness risk by availing future agriculture commodity market price knowledge to the farmer community. To fulfill this requirement, the authors have studied prediction systems study as mentioned in the next section of literature review.

\section{Literature Review}

To identify agricultural market price information providers to the farmer community and its related stake holders, the authors found that there are many web-services [24-27] and government web-portals like EChaupal [28], agriwatch [29], itcportal [30], kishan [31], indiagriline [32] and e-agriculture [33]. Also there has been contribution from many private portals and universities such as E-sagu [34], StarAgri [35], MahaAgri [36] and Lokmitra [37]. All these web applications provide data and information only and the farmer community requires is knowledge. So the authors have reviewed literature in the direction of knowledge extraction.

The authors have reviewed the literature related to knowledge extraction such as prediction of the future market value of agricultural crop before crop cultivation. There were several studies conducted which determine future market price based on archive price data. The volatility of an agriculture commodity price is very high and therefore price forecasting for decision makers in this domain has become more sensitive and challengeable compared to non-agricultural domain. The approaches used by different researchers are time series analysis with various statistical techniques and soft computing techniques such as neural network.

Govardhana Rao et.al [4] studied the seasonal variation and forecasting in wholesale price of rice in Guntur district of Andhra Pradesh. The study analyzed trends and seasonal variations of rice wholesale price from 1991 to 2010 using price forecasting model ARIMA for Guntur and Andhra Pradesh market and predicted the future trend of rice price. Their result says that for both these markets, the contribution of time to change in prices was to the extent of $73 \%$ and $80 \%$ respectively. Based on this fact, they have recommended the sale of rice. The major limitation of this study is that, it considers only percentage change of price (annual increase) in Rice and offers suggestions based on it. But, that has very little impact in agribusiness risk minimization.

Ticlavilca et.al. [5] have performed multiple predictions for agricultural commodity prices before one, two or three months. In order to obtain multiple-time-ahead predictions, the research applies the Multivariate Relevance Vector Machine (MVRVM) that is based on a Bayesian learning machine approach for regression. This study used data of monthly agricultural commodity prices to evaluate the results. In the volatile agriculture market, monthly agriculture commodity price data has very low impact to justify the prediction. Moreover, this study predicts price before one, two or three months only. In general, agriculture crop production period is more than three months. So this study does not predict price before crop cultivation and hence it is not much useful in risk management activities of agribusiness.

Manpreet Kaur et.al. [6] have discussed applications and techniques of Data mining in agriculture considering the problem of price prediction of crops. To increase the accuracy percentage of price prediction, the researchers utilized back propagation neural network prediction model using the Coimbatore market price of tomato as an example and simulated the result in MATLAB. This study attempted to forecast the prices of vegetables considering the single factor 'changes in the price of crude oil'. Other influencing parameters such as meteorological and fiscal could also have had much impact in forecasting vegetable prices which were not considered in this study. Moreover, sample size considered to conduct the study is only of previous three years, which is a very short period for agriculture price prediction application.

Linwood Hoffman [7] has developed a model to forecast the seasonal average of the agriculture commodity 'Corn' using future prices. The research has used parameters such as basis value, marketing weights and composite of monthly futures and cash prices instead of only archival price, to forecast the seasonal average 
U.S. corn farm price. There is no significant difference found between result of this study and the projection of U.S. Department of Agriculture.The main problem faced in this study is to have the value of parameter 'cash price received' and marketing weights. Cash price data is an aggregation of monthly data and marketing weights data is of 5-years moving average of these monthly weights. So, daily basis forecasting is not possible. In this way, this study gives us a superficial prediction analysis instead of in-depth prediction analysis.

Wen HUANG et.al. [8] checked the role of high frequency data in forecasting agricultural commodity futures. The study used Realized GARCH model developed by Hansen, Huang and Shek (2012) to estimate and forecast price volatility for agricultural commodity futures. The main focus of this study was to compare realised GARCH model with GARCH and EGARCH model. To improve forecasted result, this study did not apply any evaluation criteria and forecasting methodology.

All the above mentioned studies predict price in agriculture domain on their archival price data only. The prediction based only on price data may not be so appropriate as it depends on many other factors such as meteorological and market demand and supply mechanism. In this context, the author started studying the literature regarding the contribution of meteorological parameters in the prediction systems. Other data mining studies have been carried out immensely in the sub domain of agriculture such as utilization of Information Technology in agriculture $[09,10,11$, and 12], Surveys of data mining techniques in agriculture [13, 14, 15, 16, and 17] and other farm management activities in agriculture [18, 19, 20, 21, 22, and 23].

\section{Experiment Methodology}

The authors have collected the data from the Agriculture Marketing web portal, Govt. of India [38] from 1st January 2004 to 31st August 2016 for 'Surat' APMC, Gujarat state of India. Out of these data sets 1st January 2004 to 31 August 2015 was set as training data to train neural network. From 1st September 2015 to August 2016 was set as testing data to validate trained neural network. Pre-processing has been done and has been clubbed into a single file for the selected commodity. The authors have selected ten different agriculture commodities for the entire said period of the analysis as shown in Table-1 in this paper. The Pre-processed data then gets converted into time series data, in which one attribute belongs to the time factor and data file is generated for each agriculture commodity for further analysis.

Such pre-processed data then given to ANN tool of MATLAB and predictive analysis is performed. An Artificial neural Network is abbreviated as ANN. It is a type of black box technology which is used as predictive model. For each commodity, Artificial Neural Network was created with 10 hidden layers and algorithms used was 'Feed forward Back Propagation', Training function was 'TRAINLM', adaption learning function was 'LEARNGDM', performance evaluator was 'MSE', the number of neurons were 10 and Transfer function was 'TANSIG'. In training, the total number of epochs was 1000. Then the authors trained Neural Network and tried to achieve a higher regression co-efficient value (R) which is statistically significant for better fit curve. After completion of training, the authors simulated the network using 'Sample' data-Testing data as input and 'Predicted' data as output. In this study such time series data given to neural network for training and generated predicted agriculture commodity market price as an output as per given below steps.

1. First step is to load pre-processed data from training time series data set.

2. Perform classification on data and get initial accuracy from trained neural network.

3. Set improved accuracy of the neural network in various iterations.

4. After having trained neural network, supply testing data to check accuracy.

5. Generate predicted agriculture market price from its output parameter.

6. Compare output parameters with actual agriculture market price and calculate MAPE.

7. Find out performance by calculating accuracy percentage as 100 - MAPE.

\section{Experiments Result}

After having output from neural network, predicted value compared with actual value and error was calculated for each record. Then such records error was calculated using the forecasting measures such as Mean Absolute Deviation (MAD), Mean Square Error (MSE) and Mean Absolute Percentage Error (MAPE) for that specific commodity. This process continues for all selected ten commodities and MAD, MSE and MAPE was calculated using following formula. Experiments results of all ten commodity displayed in Table-1. For the visual convenience, the authors have shown two commodities accuracy chart as shown in Figure-1 and Figure-2 for Brinjal and Potato respectively.

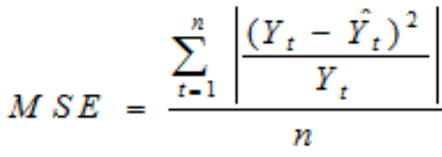

Where, $Y=$ Actual Price of $\mathrm{t}^{\text {th }}$ observation

$\hat{Y}=$ Predicted price of $t^{\text {th }}$ observation

$n=$ Number of observations

$Y . \neq 0$ 


$$
\begin{aligned}
& M A D=\frac{\sum_{t=1}^{n}\left|\left(Y_{t}-\hat{Y}_{t}\right)\right|}{n} \\
& \text { Where, } Y=\text { Actual Price of } \mathrm{t}^{\text {th }} \text { observation } \\
& \hat{Y}=\text { Predicted price of } \mathrm{t}^{\text {th }} \text { observation } \\
& n=\text { Number of observations } \\
& Y \neq 0 \\
& M A P E=\frac{\sum_{i=1}^{n}\left|\frac{\left(Y_{t}-\hat{Y}_{t}\right)}{Y_{t}}\right|}{n} \times 100
\end{aligned}
$$

\begin{tabular}{|c|c|c|c|c|}
\hline \multirow[t]{2}{*}{ Agriculture Commodity } & \multicolumn{4}{|c|}{ (Artificial Neural Network) } \\
\hline & MAD & $\operatorname{MSE}\left(\times 10^{5}\right)$ & MAPE & ACCURACY \% \\
\hline Bhindi(Ladies Finger) & 43.67 & 1.40 & 0.78 & 99.22 \\
\hline Brinjal & 93.00 & 3.98 & 22.43 & 77.57 \\
\hline Cauliflower & 30.48 & 4.27 & 3.44 & 96.56 \\
\hline Cabbage & 19.97 & 3.36 & 6.02 & 93.98 \\
\hline Green Chilly & 50.63 & 1.43 & 6.95 & 93.05 \\
\hline Lemon & 402.39 & 1.16 & 12.02 & 87.98 \\
\hline Onion & 201.32 & 1.79 & 21.93 & 78.07 \\
\hline Potato & 22.37 & 3.43 & 3.55 & 96.45 \\
\hline Tomato & 93.92 & 1.69 & 17.68 & 82.32 \\
\hline Surat Beans (Papdi) & 189.34 & 3.36 & 6.02 & 93.98 \\
\hline
\end{tabular}

Table-1 Accuracy Percentage Analysis for various Agriculture commodities

Table-1 shows that, the soft computing techniques such as neural network for the time series analysis can do better and gives higher amount of accuracy. MAD, MSE and MAPE can be calculated as per given formula. Although agriculture commodity market in India is very fluctuating market, but still the author achieved moderate accuracy except two commodities Brinjal and Tomato. So such predicted price in the form of knowledge ultimately helps the farmer community in their decision making and thereby minimizes risk in their agriculture business.

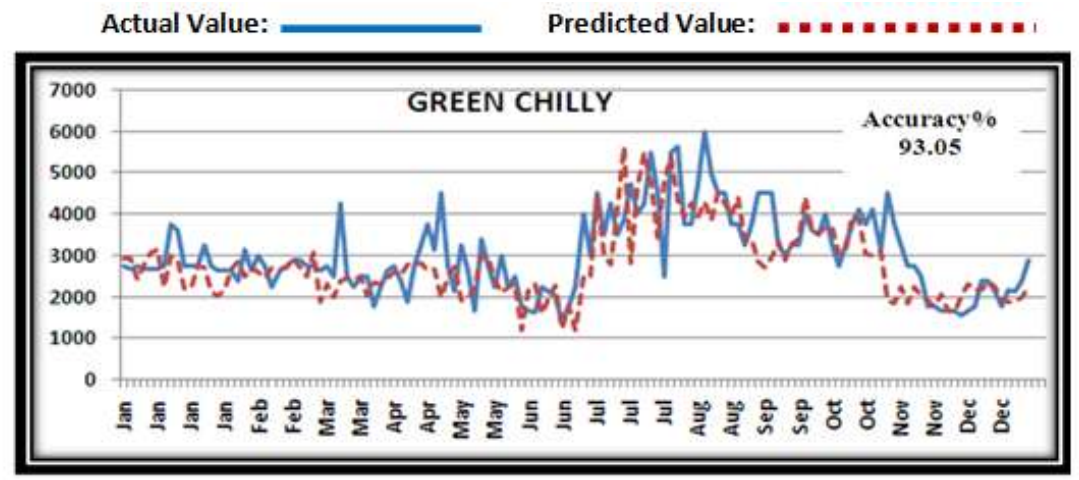

Figure-1 Market Price Prediction for Agriculture Commodity Green Chilly

Actual Value:

Predicted Value:

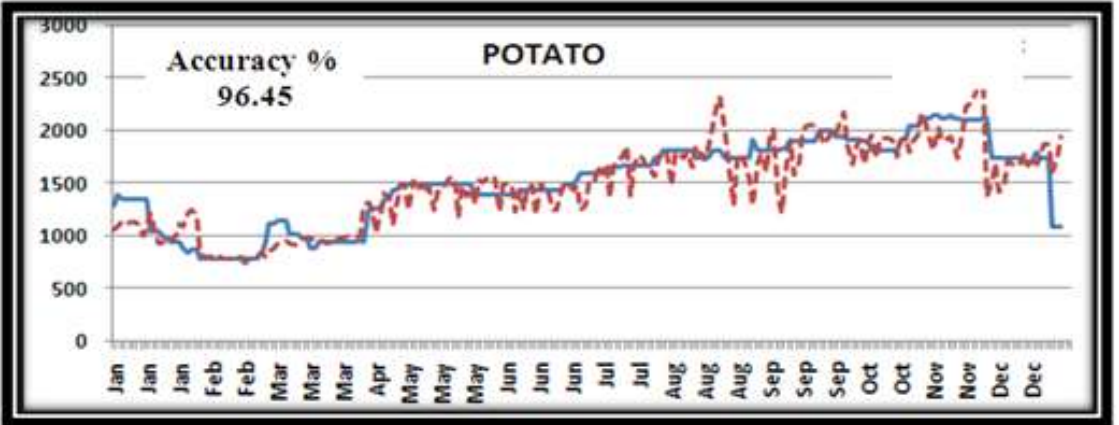

Figure-2 Market Price Prediction for Agriculture Commodity Potato 
As shown in Figure-1 and Figure-2, continuous line displayed the actual price and dotted line represents the predicted market price. Figure-1 shows that from June end to August beginning the price of the agriculture commodity Green Chilly remains high. Similarly as shown in Figure-2, the market price of agriculture commodity Potato starts rising from July end and continue up to November end. So farmer community can take benefit of this knowledge and accordingly plan to cultivate the respective crop so that the maximum profit can be earned at the time of cropping of that agriculture commodity.

\section{Conclusion}

In this paper the authors have discussed about the agribusiness challenges and a way to deal with such challenges. The authors predict agriculture commodity market price with reasonable accuracy level and thereby offer help to the farmer community in their decision making of agriculture activities such as planting date, cultivar's choice and agribusiness decision such as when to sell the said agriculture commodity to avail the maximum market price for that agriculture commodity. So the farmer community can avoid guess work and perform agribusiness activities using generated agricultural knowledge in the form of predicted agriculture commodity market price. All these activities ultimately result in minimization of risk in agribusiness and thereby help the farmer community to achieve their ultimate goal of profit making.

\section{References}

\section{Journal Papers:}

[1] Twelfth five year plan (2012-2017): Planning Commission, Govt. of India, Vol.2 (1), 2013, pp.1-50.

[2] Final Report of Committee of State Ministers: In-charge of Agriculture Marketing to Promote Reforms. Ministry of Agriculture Department of Agriculture and Co-operation Government of India, 2013, pp.1-43.

[3] Ghadiyali, Tejas; Lad, Kalpesh and Patel, Bankim.: Agriculture Intelligence: An emerging tool for farmer community., Proceedings of second international conference on "Emerging Application of Information technology, EAIT 2011; Vol.1(1), pp.313-316. IEEE DOI 10.110819/EAIT 2011.36.

[4] Govardhana Rao G., Solmonrajupaul K., Vishnu Sankarrao D., Dayakar G.: Seasonal Variations and Forecasting in Wholesale Prices of Rice (Paddy) In Guntur District of Andhra Pradesh In: International Journal of Development Research, Vol.4(11), Andhra Pradesh, 2014, 2418-2422.

[5] Ticlavilca, A. M., Dillon M. Feuz and Mac McKee:Forecasting Agricultural Commodity Prices Using Multivariate Bayesian Machine Learning Regression In: Proceedings of the NCCC-134 Conference on Applied Commodity Price Analysis, Forecasting, and Market Risk Management. St.Louis, MO. 2010, April 19-20

[6] Manpreet Kaur, Heena Gulati, Harish Kundra: Data Mining in Agriculture on Crop Price Prediction: Techniques and Applications In: International Journal of Computer Application Vol.99(12), 2014, 1-3

[7] Linwood Hoffman: Using Futures Prices to Forecast the Season-Average U.S. Corn Price In: Proceedings of the NCR-134 Conference on Applied Commodity Price Analysis, Forecasting, and Market Risk Management St. Louis, 2004, April 19-20,

[8] Wen HUANG, Zhuo HUANG, Marius MATEI, Tianyi WANG: Price Volatility Forecast for Agricultural Commodity Futures: The Role of High Frequency Data In: Romanian Journal of Economic Forecasting Vol.4,2012, 83-103

[9] G. Nasrin Fathima, R.Geetha: Agriculture Crop Pattern Using Data Mining Techniques In: International Journal of Advanced Research in Computer Science and Software Engineering Vol.4(5), 2014, pp.781-786

[10] Raorane A.A., Kulkarni R.V.: Data Mining: An effective tool for yield estimation in the agricultural sector In: International Journal of Emerging Trends \& Technology in Computer Science (IJETTCS) Vol.1(2), 2012

[11] Geraldin B., Bobby D., Bartolome T.: Agricultural Crops Classification Models Based on PCA-GA Implementation in Data Mining In: International Journal of Modelling and Optimization Vol.4(5), 2014, 375-382

[12] P.Bhargavi, S.Jyothi: Applying Naive Bayes Data Mining Technique for Classification of Agricultural Land Soils In: IJCSNS International Journal of Computer Science and Network Security Vol.9(8),2009, ), 117-122

[13] Raorane A.A., Kulkarni R.V.: Data Mining: An effective tool for yield estimation in the agricultural sector In: International Journal of Emerging Trends \& Technology in Computer Science (IJETTCS) Vol.1(2).2012

[14] Yethiraj N G: Applying Data Mining Techniques in the field of Agriculture and Allied Sciences In: International Journal of Business Intelligent Vol.1(2), pp.72-76. Integrated Intelligent Research (IIR), 2012

[15] Ms.Kalpana.R, Dr.Shanthi.N , Dr.Arumugam.S: A Survey on Data Mining Techniques in Agriculture In: International Journal of Advances in Computer Science and Technology Vol.3(8), 2014, pp.426-431.

[16] D. Ashok Kumar N. Kannathasan: A Survey on Data Mining and Pattern Recognition Techniques for Soil Data Mining In: IJCSI International Journal of Computer Science Issues, Vol. 8(3), 2011, 422-428.

[17] Farah Khan, Divakar Singh: Association Rule Mining in the field of Agriculture In: International Journal of Scientific and Research Publications Vol.4(7), 2014, 1-4

[18] Vishwanath.B.C, S.A.Madival, Sharanbasava Madole: Recognition of Fruits in Fruits Salad Based on Color and Texture Features In: International Journal of Engineering Research \& Technology (IJERT) Vol.1(7), 2012, 1-6.

[19] G. Nasrin Fathima, R.Geetha: Agriculture Crop Pattern Using Data Mining Techniques In: International Journal of Advanced Research in Computer Science and Software Engineering Vol.4(5), 2014,781-786.

[20] P. Revathi, Dr.M.Hemalatha: Categorize the Quality of Cotton Seeds Based on the Different Germination of the Cotton Using Machine Knowledge Approach In: International Journal of Advanced Science and Technology Vol.36, 2011, 9-14.

[21] Geraldin B., Bobby D., Bartolome T.: Agricultural Crops Classification Models Based on PCA-GA Implementation in Data Mining In: International Journal of Modelling and Optimization Vol.4(5), 2014,375-382.

[22] Jeysenthil.KMS, Manikandan.T, Murali.E: Third Generation Agricultural Support System Development Using Data Mining In: International Journal of Innovative Research in Science, Engineering and Technology Vol.3(3), 2014, 9923-9930.

[23] P.Bhargavi, S.Jyothi: Applying Naive Bayes Data Mining Technique for Classification of Agricultural Land Soils In: IJCSNS International Journal of Computer Science and Network Security Vol.9(8), 2009,117-122. 


\section{Web Sources}

[1] http://agri.gujarat.gov.in/ Last visited on 12th September 2016 at 10.45 p.m

[2] https://ikhedut.gujarat.gov.in Last visited on 12 September 2016 at 10 p.m

[3] www.emitra.gov.in Last visited on 15th August 2016 at 6.00 p.m.

[4] www.bhoomi.karnataka.gov.in Last visited on 21 August 2016 at 10.30 p.m.

[5] www.echoupal.com visited on 2nd October 2015 at 10 p.m.

[6] www.agriwatch.com visited on 11th October 2015 at 11.20 a.m.

[7] www.itcportal.com visited on 14 October 20156.50 p.m.

[8] www.kishan.com visited on 5th December 2015 at 6.30 p.m.

[9] www.indiagriline.com visited on 22nd November 2015 at 1.40 p.m.

[10] www.e-agriculture.org visited on 30th November 7.30 p.m.

[11] www.agriculture.iiit.ac.in (esagu) Last visited on 18th August 2015 at 5 p.m.

[12] www.staragri.com Last visited on 11 th July 2015 at 11 a.m.

[13] www.mahaagri.gov.in Last visited on 11th July 2015 at 12.15 p.m.

[14] www.hp.gov.in (Lokmitra Kendra) Last visited on 11th July 2015 at 5 p.m.

[15] www.agmarknet.nic.in, visit on 11th December 2015 at 4.00 p.m.

Dr.Tejas Ghadiyali, MCA, Ph.D. is an Assistant Professor at Udhna Academy College , Surat Gujarat, India

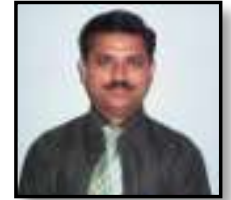
and has 14 years teaching experience. His research interests lie in Agriculture Informatics, Data Mining and Predictive Modeling. He has presented and published more than 10 research papers in National and International conferences / reputed journals. He is serving as a Member of Board of Studies (Computer Science \& Information Technology), VNSGU, Surat, Gujarat, India since 2009. He can be contacted at tejas_ghadiyali@ rediffmail.com

Dr. Kalpesh Lad, MCA, Ph.D. is a recognized Ph. D. supervisor in faculty of Computer Science and

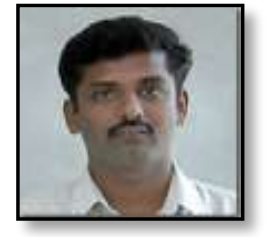

Technology at Uka Tarsadia University, Bardoli, Gujarat, India. He has 15 Years teaching experience at post graduation level. His area of interest is Business Intelligence and Compiler Construction. He has published more than 15 National and International research paper in reputed journals. . He is serving as a Member of Board of Studies (Computer Science \& Information Technology, an active member of 'Syllabus Design Committee' of Master Course, 'Examiner Appointment Committee' and other University related corecommittee at Uka Tarsadia University. He can be contacted at kalpesh.lad@utu.ac.in 